\title{
Punicalagin Suppresses Mediators Involved in Labor Onset and Progression in vitro
}

\author{
${ }^{1,2}$ Caitlyn Nguyen-Ngo, ${ }^{3,4,5}$ Jane C Willcox and ${ }^{1,2}$ Martha Lappas \\ ${ }^{1}$ Obstetrics, Nutrition and Endocrinology Group, Department of Obstetrics and Gynecology, \\ University of Melbourne, Heidelberg, Victoria, Australia \\ ${ }^{2}$ Mercy Perinatal Research Centre, Mercy Hospital for Women, Heidelberg, Victoria, Australia \\ ${ }^{3}$ School of Allied Health, College of Science, Health and Engineering, La Trobe University, Bundoora, Victoria, Australia \\ ${ }^{4}$ Deptartment of School of Human Movement and Nutrition Sciences, University of Queensland, Brisbane, Australia \\ ${ }^{5}$ Centre for Quality and Patient Safety Research - Epworth HealthCare Partnership, Institute of Health Transformation, \\ School of Nursing and Midwifery, Deakin University, Burwood, Australia
}

Article history

Received: 17-03-2021

Revised: 04-07-2021

Accepted: 22-08-2021

Corresponding Author:

Caitlyn Nguyen-Ngo

Obstetrics, Nutrition and

Endocrinology Group,

Department of Obstetrics and

Gynaecology, University of

Melbourne, Heidelberg,

Victoria, Australia

Email: nncaitlyn@gmail.com

\begin{abstract}
Spontaneous preterm birth is the leading cause of neonatal morbidity and mortality. Inflammation plays a central role in the activation of myometrial contractions and rupture of fetal membranes associated with spontaneous preterm birth. The pomegranate polyphenol punicalagin is known to possess anti-inflammatory properties. In this study, we aimed to determine the effect of punicalagin on pro-inflammatory and pro-labor mediators in an in vitro model of intrauterine inflammation associated with preterm birth. Primary human cells isolated from myometrium, decidua and fetal membranes (amnion mesenchyme) were stimulated with or without IL1B or TNF, in the absence or presence of punicalagin. Punicalagin blocked inflammation-induced expression of pro-inflammatory cytokines, chemokines and extracellular matrix degrading enzymes in primary myometrial, decidual and amnion cells. Punicalagin also suppressed inflammation-induced myometrial activation as evidenced by a decrease in PTGS2 mRNA expression, $\mathrm{PGF}_{2 \alpha}$ secretion and myometrial cell contractility in situ. Overall, punicalagin may block pro-inflammatory and pro-labor mediators in human gestational tissues. Further study should identify if punicalagin can delay LPS-induced spontaneous preterm birth in an in vivo mouse model.
\end{abstract}

Keywords: Punicalagin, Preterm Birth, Myometrial Activation, Membrane Rupture, Inflammation

\section{Introduction}

Spontaneous preterm birth is the leading cause of neonatal morbidity and mortality and affects up to $20 \%$ of all pregnancies (Beck et al., 2010). Survivors of preterm birth face lifelong neurological disabilities, including cerebral palsy, developmental delay and hearing and visual impairment (Mwaniki et al., 2012). In addition to these significant health complications, spontaneous preterm birth creates heavy economic burden on the healthcare system - preterm birth leads to initial hospitalisation costs of up to US\$ 576972 per baby born at 24 weeks and continued long-term public sector costs of US\$39 329 per preterm survivor reaching 18 years (Petrou et al., 2019).

Inflammation is a known trigger for more than half of all spontaneous preterm births (75\%) (Goldenberg et al., 2000, Romero et al., 1988, Gilman-Sachs et al., 2018). Infectious or sterile pro-inflammatory insults activate the maternal immune system to induce a pro-inflammatory cascade of events, including leukocyte infiltration into the gestational tissues (Thomson et al., 1999, Hamilton et al., 2012) and upregulation of pro-inflammatory cytokines (IL1A, IL1B, IL6, GM-CSF, TNF) and Chemokines (CCL and CXCL chemokines). These cytokines induce further production of pro-inflammatory cytokines and chemokines (Lappas, 2017, Lappas et al., 2006, Lim et al., 2017) and other pro-labor mediators (Kumar et al., 2006, Rauk and Chiao, 2000, Chen et al., 2020). These include the contraction-associated proteins prostaglandin-endoperoxide synthase 2 (PTGS2) and the uterotonic prostaglandin F2 $\alpha$ (PGF2 $\alpha$ ) to stimulate myometrial contractility and Extra cellular Matrix (ECM) degrading and remodelling enzymes to induce weakening and rupture of the fetal membranes (Vadillo-Ortega and Estrada-Gutierrez, 2005, Olson and Ammann, 2007). 
Current therapeutics to delay preterm birth are beneficial to only a specific subset of at-risk women: Progesterone is only effective in women presenting with a short cervix, while tocolytic therapies delay preterm birth for only $48 \mathrm{~h}$ (Haas et al., 2012). These modest effects are likely due to little impact of the therapeutics on the inflammatory response that drives spontaneous preterm birth. Therefore, it is essential to identify new anti-inflammatory interventions that may reduce intrauterine inflammation and ultimately prevent preterm birth and its associated lifelong consequences.

Recent evidence suggests that plant-based diets, rich in polyphenols, are associated with reduced incidence of preterm birth (Englund-Ögge et al., 2014, Myhre et al., 2013). Polyphenols are natural, plant-based compounds that have demonstrated anti-inflammatory properties (Manach et al., 2004). We have previously shown that three classes of polyphenols (flavonoids: Nobiletin, naringenin, apigenin, silibinin, luteolin and kaempferol; lignans: Honokiol; and phenolic acids: Curcumin, gallic acid) can suppress inflammation-induced expression of pro-inflammatory and pro-labor mediators in placenta, myometrium and fetal membranes (Wijesuriya and Lappas, 2018, Morwood and Lappas, 2014, Lim et al., 2014, Lim et al., 2013c, Wall et al., 2013, Nguyen-Ngo et al., 2020). Punicalagin is an ellagitannin, a type of phenolic acid, commonly found in pomegranates, East Indian almonds and the medicinal velvet bushwillow (Rothwell et al., 2013, Asres et al., 2001, Marzouk et al., 2002). Several studies report anti-inflammatory properties of punicalagin in vitro and in vivo (Bensaad et al., 2017, $\mathrm{Xu}$ et al., 2014, Kang et al., 2019, Peng et al., 2015). In murine macrophages, punicalagin inhibited LPS-induced PTGS2 mRNA expression and prostaglandin release, as well as pro-inflammatory cytokine (IL1B, IL6 and TNF) mRNA expression and release (Bensaad et al., 2017, $\mathrm{Xu}$ et al., 2014). In high-fat-diet obese mice, punicalagin inhibited cytokine (IL1B, IL6 and TNF) and Chemokine (CCL2) mRNA expression in white adipose tissue (Kang et al., 2019), while in an animal model of LPS-induced lung injury, punicalagin inhibited leukocyte infiltration and reduced cytokine (IL1B, IL6 and TNF) levels in lung tissue (Peng et al., 2015). However, there are no studies investigating the effect of punicalagin on either in vitro or in vivo models of spontaneous preterm birth.

The aim of this study was to investigate the effect of punicalagin on the expression of mediators involved in the rupture of fetal membranes and myometrial activation. IL1B and TNF are key cytokines known to induce prostaglandin pathway proteins and ECM-degrading enzymes in myometrium and fetal membranes (Lappas, 2017, Lim et al., 2017). Thus, primary human cells were isolated from pregnant non-laboring myometrium, decidua and fetal membranes (amnion mesenchymal) and incubated with IL1B or TNF to generate an in vitro model of inflammation-induced preterm birth. Myometrial cells were also used in collagen gel assays to examine the effect of punicalagin on myometrial cell contractility.

\section{Methods}

\section{Human Tissue Collection}

Mercy Hospital for Women's Research and Ethics Committee granted ethics approval (Mercy Health, Ethics approval number R04-29) for tissue collection. All participating women provided written informed consent. All experiments were then performed in accordance with relevant guidelines and regulations. Myometrium was excised from the lower uterine segment and placenta collected together with attached fetal membranes. Tissues were obtained from healthy pregnant women (body mass index $<30 \mathrm{~kg} / \mathrm{m}^{2}$ ) undergoing elective Caesarean section in the absence of labor to deliver a single healthy infant at term (37-40 weeks gestation). Women were excluded if they were smokers, or had vascular/renal complications, asthma, multiple gestations, acute fetal distress, preeclampsia, chorioamnionitis, placental abruption, or any other underlying medical conditions. All tissues were delivered to the laboratory and processed within 15 min of delivery.

\section{Primary Cell Culture}

Myometrial cells (Lim et al., 2013a), decidual cells (Araujo et al., 2018) and mesenchymal cells (Lim and Lappas, 2019) were isolated and cultured as previously described. Decidual tissue was collected from the chorion layer of fetal membranes. Cells were grown in DMEM/F12 containing $1 \%$ penicillin-streptomycin and $10 \%$ heatinactivated bovine serum at $37^{\circ} \mathrm{C}$ in a humidified incubator of $21 \% \quad \mathrm{O}_{2}$ (myometrial cells) or $8 \% \quad \mathrm{O}_{2}$ (decidual and amnion mesenchymal cells). Once confluent, cells were split into 48-well plates and treated with $1 \mathrm{ng} / \mathrm{mL}$ IL1B or $10 \mathrm{ng} / \mathrm{mL}$ TNF, with or without $10 \mu \mathrm{M}$ punicalagin. The optimised dose of punicalagin was based on previous literature (Zhong et al., 2015, Chen et al., 2012) and a dose response test (data not shown). After $20 \mathrm{~h}$ incubation, cells and media were collected separately and stored at $-80^{\circ} \mathrm{C}$ until analysis by ELISA, real-time quantitative Polymerase Chain Reaction (RT-qPCR) or gelatin zymography as detailed below. Each experiment was performed on samples obtained from 5 independent patients.

\section{Myometrial Collagen Gel Contractility Assay}

Cell contraction assays were performed as previously described (Wijesuriya and Lappas, 2018). Primary human myometrial cells were re-suspended in $0.25 \mathrm{~mL}$ DMEM/F12 (containing 10\% FBS) and mixed with $40 \mu \mathrm{L}$ collagen $(3 \mathrm{mg} / \mathrm{mL}$ collagen I from rat protein solution; Gibco $^{\mathrm{TM}}$ ) and $1 \mu \mathrm{L} 1 \mathrm{M} \mathrm{NaOH}$ by gently pipetting. The mixture was transferred to 48 -well tissue culture plates, incubated in $37^{\circ} \mathrm{C}$ to allow polymerization (approx. 30 $\mathrm{min}$ ) and then treated with $10 \mathrm{ng} / \mathrm{mL} \mathrm{TNF}$ in the absence or presence of $10 \mu \mathrm{M}$ punicalagin. The gel matrix was gently detached from the well, incubated for $50 \mathrm{~h}$ at $37^{\circ} \mathrm{C}$ and the area of the gel was determined using Image Lab software 
(Bio-Rad Laboratories, Hercules, CA, USA). Experiments were performed from myometrium obtained from 5 patients.

\section{Enzyme-Linked Immunosorbent Assay}

Media from the tissue explants were assayed using a sandwich ELISA to determine the protein concentrations of IL6, CXCL8 and GM-CSF (Life Technologies; Mulgrave, Vic, Australia) and IL1A, IL1B, CCL2, CXCL1 and CXCL5 (RnD Systems, Minneapolis, MN, USA) according to the manufacturer's instructions. The release of $\mathrm{PGF}_{2 \alpha}$ into the incubation medium was assayed using a commercially available competitive enzyme immunoassay kit according to the manufacturer's instructions (Cayman Chemical Company; Ann Arbor, MI, USA). The calculated interassay and intraassay Coefficients of Variation (CV) were all less than $10 \%$. The limit of detection (defined as 2 SD from the zero standard) were as follows: IL1A, 7.8; IL1B, 3.9; IL6, 15.6; GM-CSF, 6; CCL2, 15.6; CXCL1, 31.3; CXCL5, 15.6; and CXCL8, $12.5 \mathrm{pg} / \mathrm{mL}$.

\section{$R N A$ Extraction and $R T-q P C R$}

Total RNA was extracted from tissues using TRI Reagent (Sigma-Aldrich, Saint Louis, MO, USA) and converted to cDNA using the High Capacity cDNA Reverse Transcription Kit (Applied Biosystems, Foster City, CA, USA) as previously described (Wijesuriya and Lappas, 2018). The cDNA was diluted to $1 \mathrm{ng} / \mu \mathrm{L}$ in sterile milli-Q water. The SensiFAST ${ }^{\text {TM }}$ SYBR No-ROX Kit (Bioline, Alexandria, NSW, Australia) and $100 \mathrm{nM}$ of pre-designed and validated primers (Qiagen; Chadstone Centre, Vic, Australia) were used to perform RT-PCR on the CFX384 Real-Time PCR detection system (Bio-Rad Laboratories, Gladesville, NSW, Australia). Average gene $\mathrm{Ct}$ values for the in vitro studies were normalised against the housekeeping genes tyrosine 3-monooxygenase/tryptophan 5-monooxygenase activation protein Zeta (YWHAZ) and succinate dehydrogenase complex Subunit A (SDHA). Experimental treatment had no effect on the mRNA expression of SDHA or YWHAZ. The comparative $\mathrm{Ct}$ method was used to determine fold differences.

\section{Gelatin Zymography}

Gelatin zymography was used to assess the expression of pro MMP9 in incubation media as previously described (Lim et al., 2013b). Proteolytic activity was visualised as clear zones of lysis on a blue background of undigested gelatin. Gels were scanned using a ChemiDoc XRS system (Bio-Rad Laboratories; Gladesville, NSW, Australia) and inverted and densitometry was performed using Quantity One image analysis software (Bio-Rad Laboratories; Gladesville, NSW, Australia).

\section{Statistical Analysis}

All statistical analyses were undertaken using GraphPad Prism (GraphPad Software, La Jolla, CA, USA). Shapiro-
Wilk test was used to test the normality of all the data. Data for Fig. 1-7 were analysed by a repeated measures one-way ANOVA (with LSD post-hoc testing to discriminate among the means); non-normally distributed data were logarithmically transformed before analysis. Statistical significance was ascribed to a $\mathrm{P}$ value $\leq 0.05$. Data were expressed as mean \pm Standard Error of the Mean (SEM).

\section{Results}

Effect of Punicalagin on Pro-Inflammatory Cytokines in Primary Myometrial, Decidual and Amnion Cells

The effect of punicalagin on mRNA expression and protein secretion of pro-inflammatory cytokines in primary myometrial, decidual and amnion cells is demonstrated in Fig. 1. For all cells, the concentrations of IL1A, IL1B and GM-CSF in the incubation media were below the sensitivity of the assay.

In primary human myometrial, IL1B and TNF significantly upregulated IL1A, IL1B, IL6 and GM-CSF mRNA expression and IL6 protein concentration compared with basal (Fig. 1A-E). Punicalagin significantly suppressed IL1B-induced IL1A, IL6 and GM-CSF mRNA expression and IL6 protein concentration (Fig. 1A, C-E) and TNF-induced IL1A mRNA expression (Fig. 1A) and IL6 protein concentration (Fig. 1D). However, there was no effect of punicalagin on TNF-induced IL1B, IL6 or GM-CSF mRNA expression (Fig. 1B, C, E).

In primary human decidual cells, IL1B significantly increased IL1A, IL6 and GM-CSF mRNA expression (Fig. 1F, H, J) compared to basal and TNF increased IL1A, IL1B, IL6 and GM-CSF mRNA expression (Fig. 1FH, J) compared with basal. There was no effect of IL1B or TNF on IL6 release compared with basal (Fig. 1I). Punicalagin significantly reduced IL1B-induced IL6 protein secretion and TNF-induced IL1A and IL1B mRNA expression and IL6 release (Fig. 1F, G, I). There was, however, no effect of punicalagin on IL1B-induced IL1A, IL6 or GM-CSF mRNA expression (Fig. 1F, H, J) or TNFinduced IL6 or GM-CSF mRNA expression (Fig. 1H, J).

In primary human amnion mesenchymal cells, IL1B significantly induced IL6 mRNA expression and release (Fig. 1N, O), while TNF significantly increased IL1A, IL1B and IL6 mRNA expression and secretion (Fig. 1KO) compared with basal. There was no effect of IL1B on IL1A or GM-CSF mRNA expression (Fig. 1K, P) or TNF on GM-CSF mRNA expression (Fig. 1P). Punicalagin significantly downregulated TNF-induced IL1A and IL1B mRNA expression (Fig. 1K, L). There was no effect of punicalagin on IL1B-induced IL1A, IL6 or GM-CSF mRNA expression and IL6 secretion (Fig. 1K, N-P). There was also no effect of punicalagin on TNF-induced IL6 or GM-CSF mRNA expression and IL6 secretion (Fig. 1N-P). 

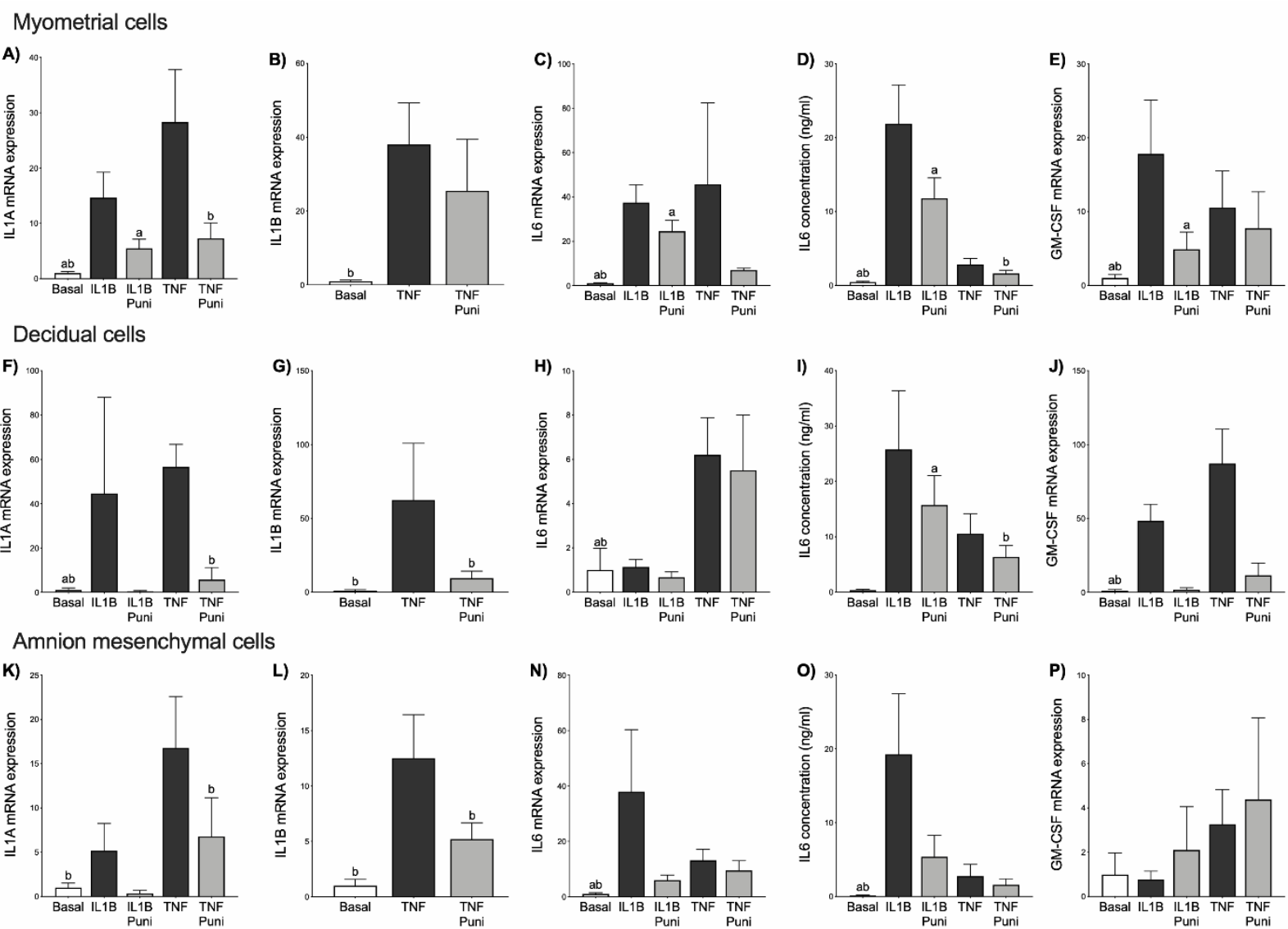

Fig. 1: Effect of punicalagin on pro-inflammatory cytokine expression and secretion in primary myometrial, decidual and amnion cells. Human primary (A-E) myometrial, (F-J) decidual and (K-P) amnion cells were incubated in $1 \mathrm{ng} / \mathrm{mL}$ IL1B or $10 \mathrm{ng} / \mathrm{mL}$ TNF with or without $10 \mathrm{~mm}$ punicalagin (Puni) for $20 \mathrm{~h}$ ( $\mathrm{n}=5$ patients). (A, F, K) IL1A, (B, G, L) IL1B, (C, H, N) IL6, and (E, J, P) GM-CSF mRNA expression were analysed by RT-qPCR. (D, I, O) IL6 concentration in the incubation medium was assayed by ELISA. All data is displayed as mean \pm SEM. Statistical significance was determined using repeated measures one-way ANOVA; the symbol 'a' denotes statistical significance compared with IL1B $(P \leq 0.05)$, while the symbol 'b' denotes statistical significance compared with TNF $(P \leq 0.05)$

Effect of Punicalagin on Pro-Inflammatory Chemokines in Primary Myometrial, Decidual and Amnion Cells

Next, we examined the effect of punicalagin on pro-inflammatory $\mathrm{CCL}$ and $\mathrm{CXCL}$ chemokines in primary myometrial cells (Fig. 2), decidual cells (Fig. 3) and amnion mesenchymal cells (Fig. 4). In primary human myometrial cells, IL1B and TNF significantly upregulated CCL2, CCL8, CXCL1, CXCL5 and CXCL8 mRNA expression and secretion compared with basal (Fig. 2A-I). Punicalagin significantly downregulated IL1B- and TNF-induced CXCL8 mRNA expression (Fig. 2H); however there was no effect of punicalagin on IL1B- and TNF-induced CCL2, CCL8, CXCL1 or CXCL5 mRNA expression (Fig 2A, C, D, F). Punicalagin significantly reduced IL1B- and TNF-induced protein secretion of CCL2, CXCL1, CXCL5 and CXCL8 (Fig 2B, E, G, I).
In primary human decidual cells, IL1B significantly increased CCL2, CXCL1, CXCL5 and CXCL8 mRNA expression and protein secretion (Fig. 3A,B,D-I). TNF significantly induced CCL2, CXCL1, CXCL5 and CXCL8 mRNA expression and CCL2, CXCL1 and CXCL8 protein concentration compared with basal (Fig. 3A, B, D-F, H, I). There was no effect of IL1B or TNF on CCL8 mRNA expression (Fig. 3C). There was also no effect of TNF on CXCL5 secretion (Fig. 3G). Punicalagin significantly reduced IL1B- and TNFinduced CXCL8 mRNA expression and CCL2, CXCL1, CXCL5 and CXCL8 protein release (Fig. 3B, E, G-I). There was no effect of punicalagin on CCL2, CCL8, CXCL1 or CXCL5 mRNA expression in the presence of IL1B or TNF (Fig. 3A, C, D, F).

In primary human amnion mesenchymal cells, IL1B and TNF upregulated CCL2, CXCL1, CXCL5 and CXCL8 mRNA expression and CXCL5 and CXCL8 protein 
secretion (Fig. 4A, D, F-I) compared with basal. IL1B also induced CXCL1 protein secretion (Fig. 4E); however, there was no effect of IL1B or TNF on CCL2 protein release (Fig. 4B) or CCL8 mRNA expression (Fig. 4C). There was also no effect of TNF on CXCL1 protein release (Fig. 4E). Punicalagin treatment significantly suppressed IL1B- induced CCL8 and CXCL8 mRNA expression and CXCL1, CXCL5, CXCL8 protein secretion (Fig. 4C, E, G-I). Punicalagin treatment also significantly reduced TNF-induced CXCL1, CXCL5 and CXCL8 mRNA expression (Fig. 4D, F, H) and CCL2 and CXCL8 protein release (Fig. 4B, I).

\section{Myometrial cells}
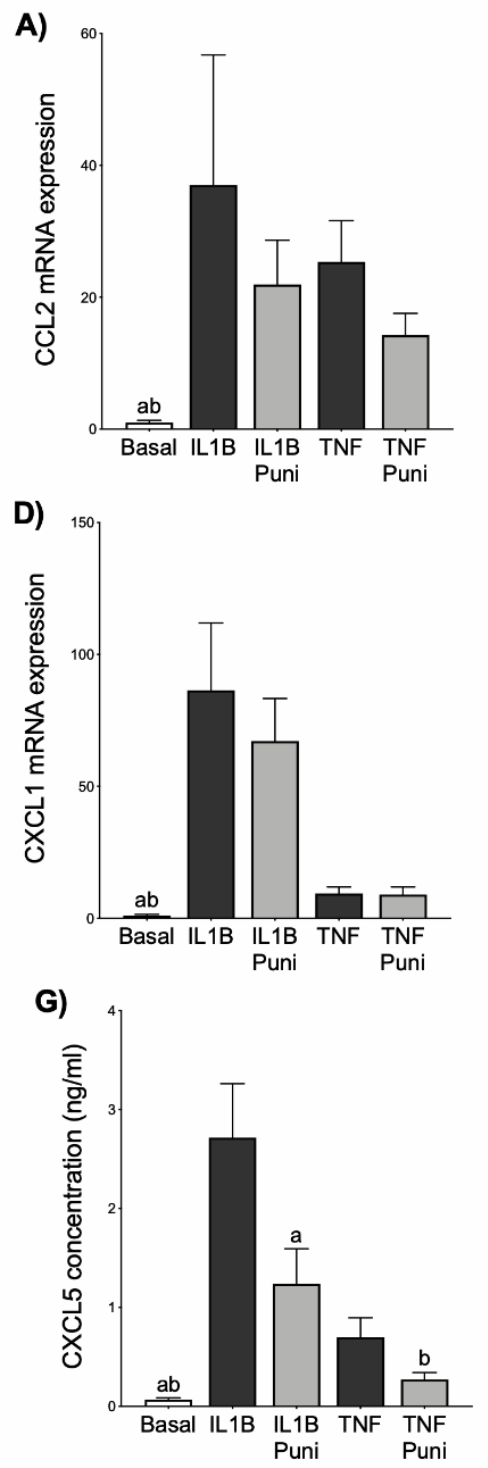
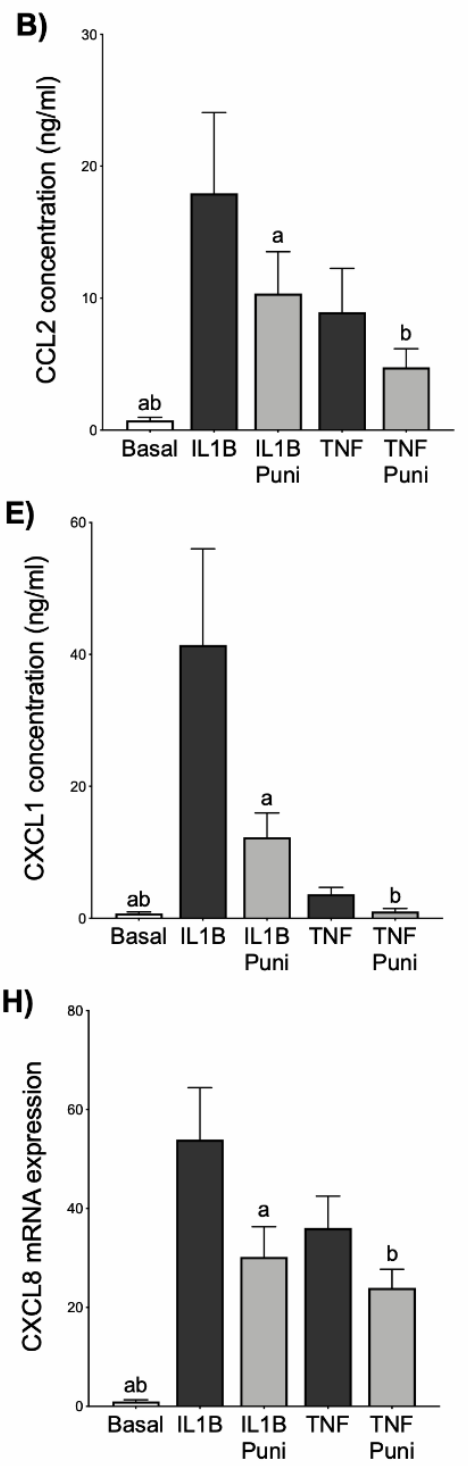
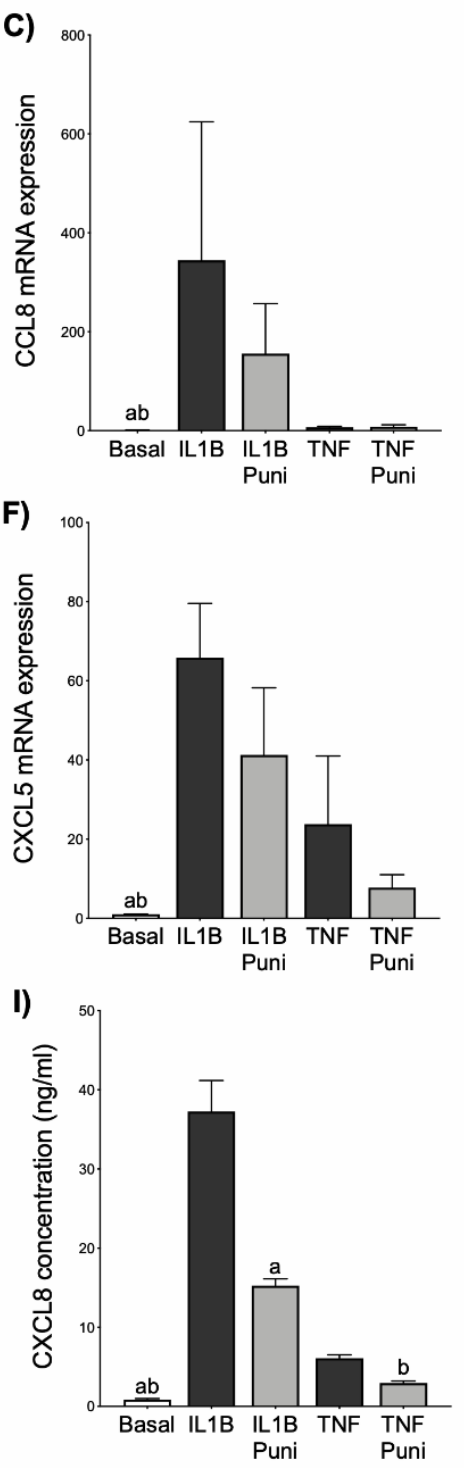

Fig. 2: Effect of punicalagin on pro-inflammatory chemokine expression and secretion in primary myometrial cells. Human primary myometrial cells were incubated in $1 \mathrm{ng} / \mathrm{mL}$ IL1B or $10 \mathrm{ng} / \mathrm{mL}$ TNF with or without $10 \mu \mathrm{m}$ punicalagin (Puni) for $20 \mathrm{~h}$ ( $\mathrm{n}=5$ patients). (A,C,D,F,H) CCL2, CCL8, CXCL1, CXCL5 and CXCL8 mRNA expression were analysed by RT-qPCR. (B,E,G,I) CCL2, CXCL1, CXCL5 and CXCL8 concentrations in the incubation medium were assayed by ELISA. All data is displayed as mean \pm SEM. Statistical significance was determined using repeated measures one-way ANOVA; the symbol ' $a$ ' denotes statistical significance compared with IL1B $(P \leq 0.05)$, while the symbol ' $b$ ' denotes statistical significance compared with TNF $(P \leq 0.05)$ 


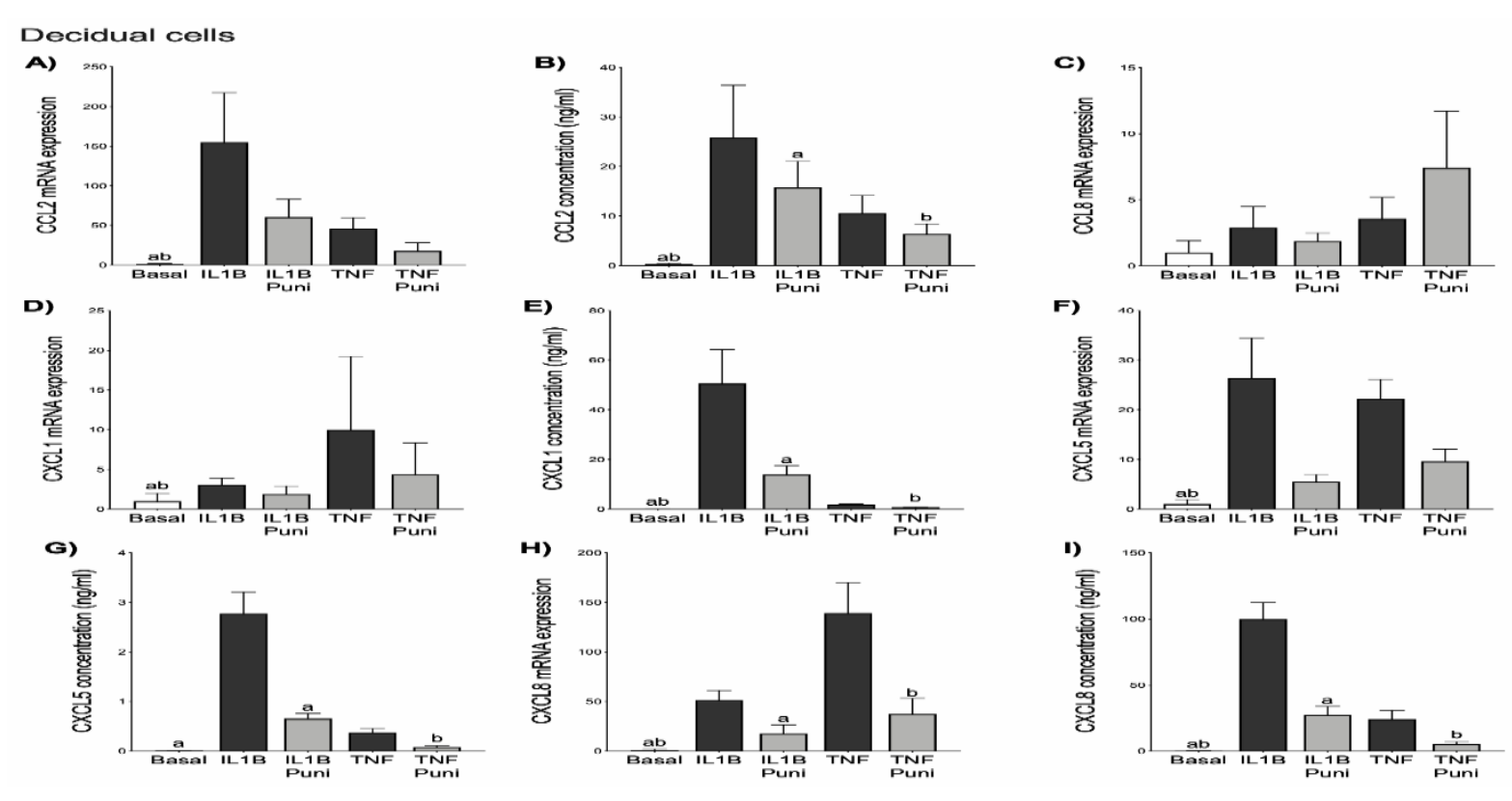

Fig. 3: Effect of punicalagin on pro-inflammatory chemokine expression and secretion in primary decidual cells. Human primary decidual cells were incubated in $1 \mathrm{ng} / \mathrm{mL}$ IL1B or $10 \mathrm{ng} / \mathrm{mL}$ TNF with or without $10 \mu \mathrm{m}$ punicalagin (Puni) for $20 \mathrm{~h}$ ( $\mathrm{n}=5$ patients). (A,C,D,F,H) CCL2, CCL8, CXCL1, CXCL5 and CXCL8 mRNA expression were analysed by RT-qPCR. (B,E,G,I) CCL2, CXCL1, CXCL5 and CXCL8 concentrations in the incubation medium were assayed by ELISA. All data is displayed as mean \pm SEM. Statistical significance was determined using repeated measures one-way ANOVA; the symbol 'a' denotes statistical significance compared with IL1B $(P \leq 0.05)$, while the symbol 'b' denotes statistical significance compared with $\mathrm{TNF}(P \leq 0.05)$
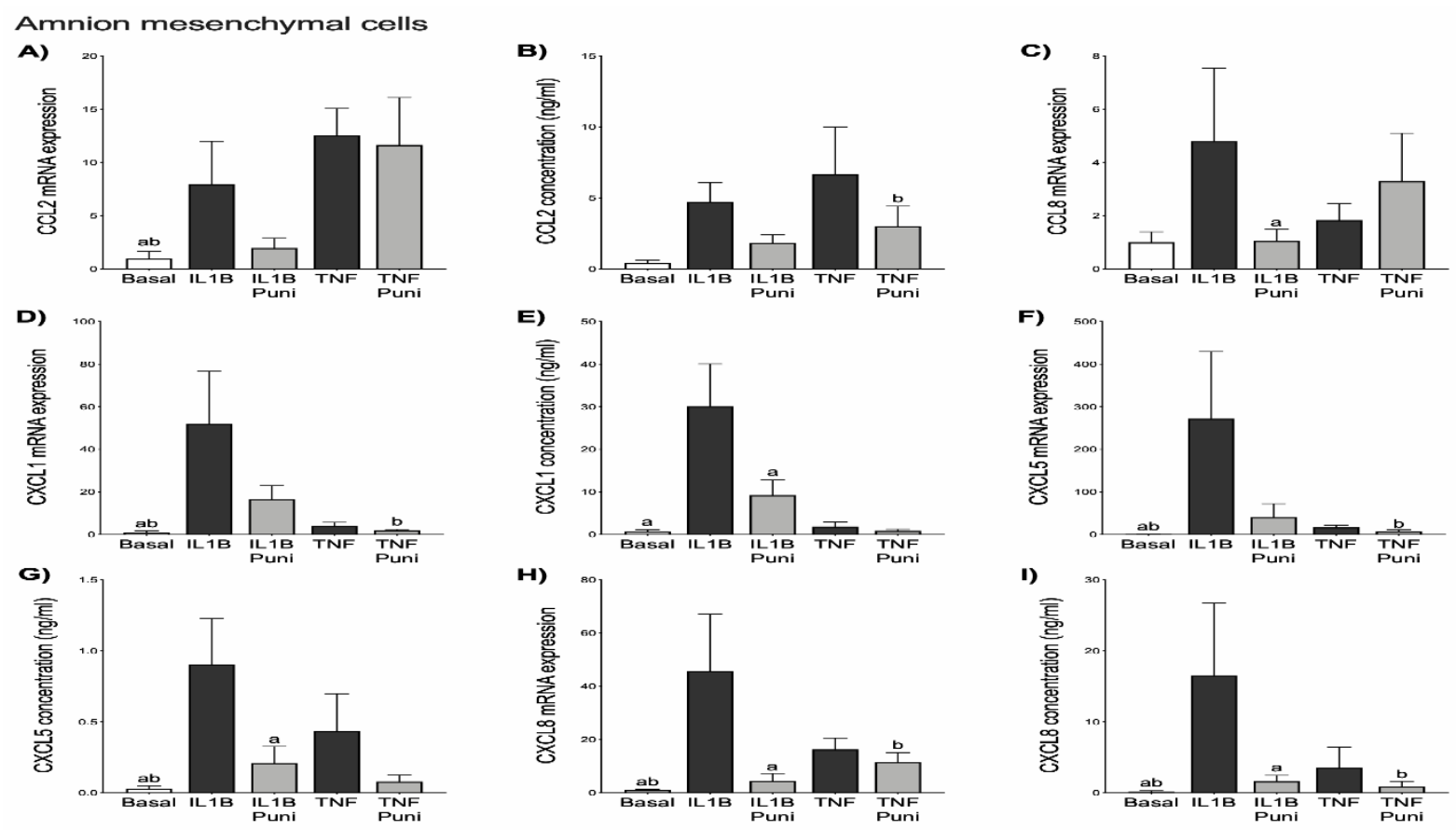

Fig. 4: Effect of punicalagin on pro-inflammatory chemokine expression and secretion in primary amnion cells. Human primary amnion cells were incubated in $1 \mathrm{ng} / \mathrm{mL}$ IL1B or $10 \mathrm{ng} / \mathrm{mL}$ TNF with or without $10 \mu \mathrm{M}$ punicalagin (Puni) for $20 \mathrm{~h}$ (n = 5 patients). (A,C,D,F,H) CCL2, CCL8, CXCL1, CXCL5 and CXCL8 mRNA expression were analysed by RT-qPCR. (B,E,G,I) CCL2, CXCL1, CXCL5 and CXCL8 concentrations in the incubation medium were assayed by ELISA. All data is displayed as mean \pm SEM. Statistical significance was determined using repeated measures one-way ANOVA; the symbol ' $a$ ' denotes statistical significance compared with IL1B $(P \leq 0.05)$, while the symbol 'b' denotes statistical significance compared with $\mathrm{TNF}(P \leq 0.05)$ 


\section{Effect of Punicalagin on the Prostaglandin Pathway in Primary Myometrial and Decidual Cells}

Myometrial contractions are mediated through the prostaglandin pathway, where PTGS2 is the rate-limiting factor for the production of prostaglandins, such as $\mathrm{PGF}_{2}$ (Olson, 2003). Prostaglandins induce myometrial contractility by binding with its Prostaglandin F Receptor (PTGFR) (Olson, 2003) and contribute to the propagation of the pro-inflammatory cycle (Leimert et al., 2019). In this study, IL1B and TNF significantly increased PTGS2 mRNA expression and $\mathrm{PGF}_{2 \alpha}$ concentration in primary human myometrial cells compared with basal (Fig. 5A, B). Punicalagin significantly blunted IL1B-induced PTGS2 mRNA expression and IL1B- and TNF-induced $\mathrm{PGF}_{2 \alpha}$ secretion (Fig. 5A, B). There was, however, no effect of punicalagin on TNF-induced PTGS2 mRNA expression (Fig. 5A).

Decidua is also known to contribute to production of prostaglandins which can induce myometrial contractions (Skinner and Challis, 1985). In this study, IL1B significantly upregulated $\mathrm{PGF}_{2 \alpha}$ secretion in primary human decidual cells compared with basal, but there was no effect of TNF on $\mathrm{PGF}_{2 \alpha}$ secretion (Fig. 5D). There was also no effect of IL1B or TNF on PTGS2 mRNA expression (Fig. 5C). Punicalagin treatment significantly blocked both IL1B- and TNF-induced $\mathrm{PGF}_{2 \alpha}$ concentration (Fig. 5D); however, there was no effect of punicalagin on PTGS2 mRNA expression (Fig. 5C).
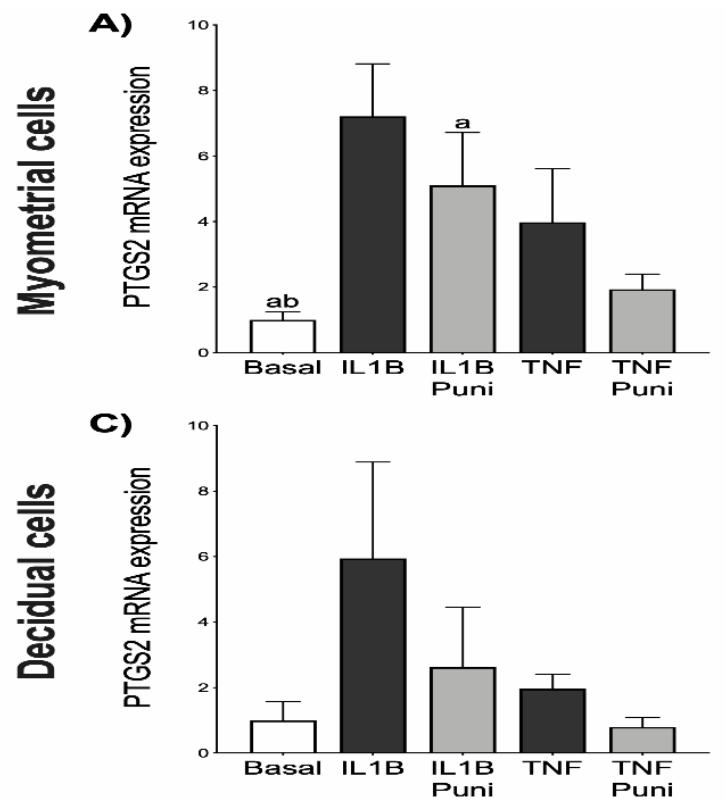

\section{Effect of Punicalagin on Myometrial Cell Contractility}

Given the effects of punicalagin on the prostaglandin pathway, we explored the effect of punicalagin on myometrial cell contractility using a 3D collagen gel assay (Fig. 6). Primary human myometrial cells were embedded in collagen gels and stimulated with TNF with or without punicalagin treatment. TNF significantly reduced collagen gel area compared with basal by $35.8 \%$, indicating increased myometrial cell contraction. Punicalagin co-treatment reversed collagen gel shrinkage by $103.9 \%$ compared with TNF, suggesting that punicalagin blocked myometrial cell contraction.

\section{Effect of Punicalagin on Matrix Metalloproteinases in Primary Decidual and Amnion Cells}

Matrix metalloproteinases are enzymes involved in remodelling and degradation of the extracellular matrix in the fetal membranes. Inflammation stimulates production of enzymes, such as MMP1, MMP3, MMP9 and MMP13, that target various cell populations in the fetal membranes to induce weakening and rupture of the fetal membranes (Weiss et al., 2007). Thus, we sought to investigate the effect of punicalagin on the mRNA expression of MMP1, MMP3, MMP9 and MMP13 in primary decidual and amnion mesenchymal cells (Fig. 7).

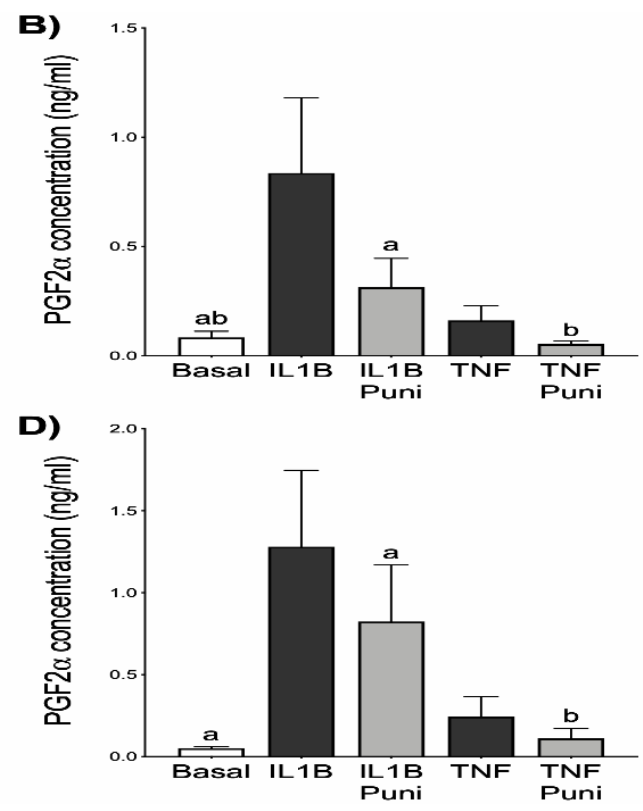

Fig. 5: Effect of punicalagin on COX-2-prostaglandin pathway proteins in primary myometrial and decidual cells. Human primary $(\mathrm{A}, \mathrm{B})$ myometrial and (C,D) decidual cells were incubated in $1 \mathrm{ng} / \mathrm{mL}$ IL1B or $10 \mathrm{ng} / \mathrm{mL}$ TNF with or without $10 \mu \mathrm{m}$ punicalagin (Puni) for $20 \mathrm{~h}(\mathrm{n}=5$ patients). (A, C) PTGS2 mRNA expression was analysed by RT-qPCR. (B, D) PGF $2 \alpha$ concentrations in the incubation media were analysed by ELISA. All data is displayed as mean \pm SEM. Statistical significance was determined using repeated measures one-way ANOVA; the symbol 'a' denotes statistical significance compared with IL1B $(P \leq 0.05)$, while the symbol 'b' denotes statistical significance compared with TNF $(P \leq 0.05)$ 


\section{Myometrial cells}

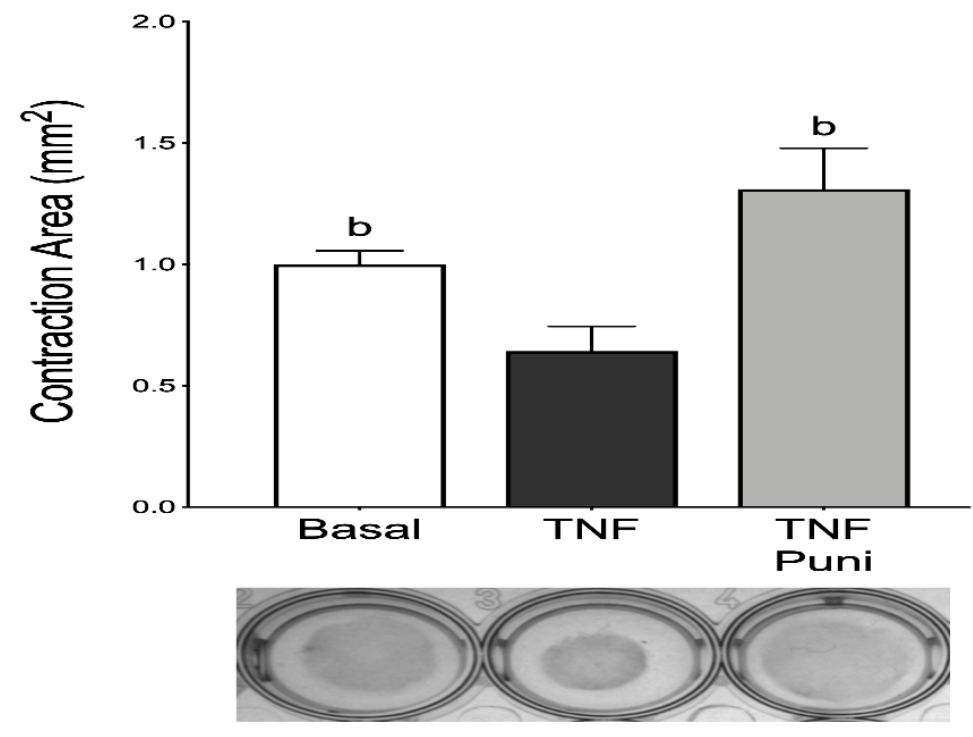

Fig. 6: Effect of punicalagin on human primary myometrial cell contraction. Collagen gel cell contraction assays were performed using 3D collagen gels embedded with human primary myometrial cells and incubated in $10 \mathrm{ng} / \mathrm{mL}$ TNF, with or without $10 \mu \mathrm{m}$ Puni for $50 \mathrm{~h}(\mathrm{n}=4$ patients). The area of the gel was determined using Chemidoc MP. Representative gel contraction image from 1 patient is also shown. All data is displayed as mean \pm SEM. Statistical significance was determined using repeated measures one-way ANOVA; the symbol 'b' denotes statistical significance compared with TNF $(P \leq 0.05)$

\section{Decidual cells}
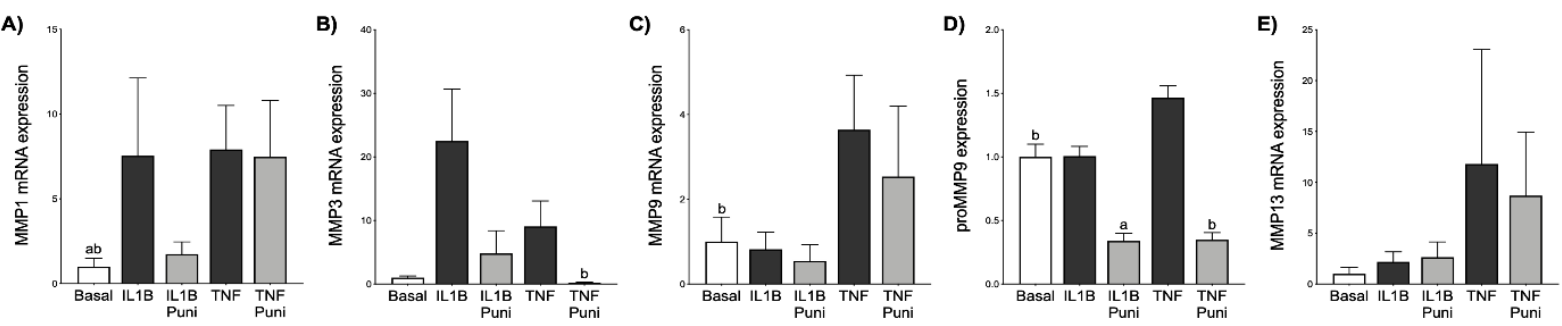

\section{Amnion mesenchymal cells}
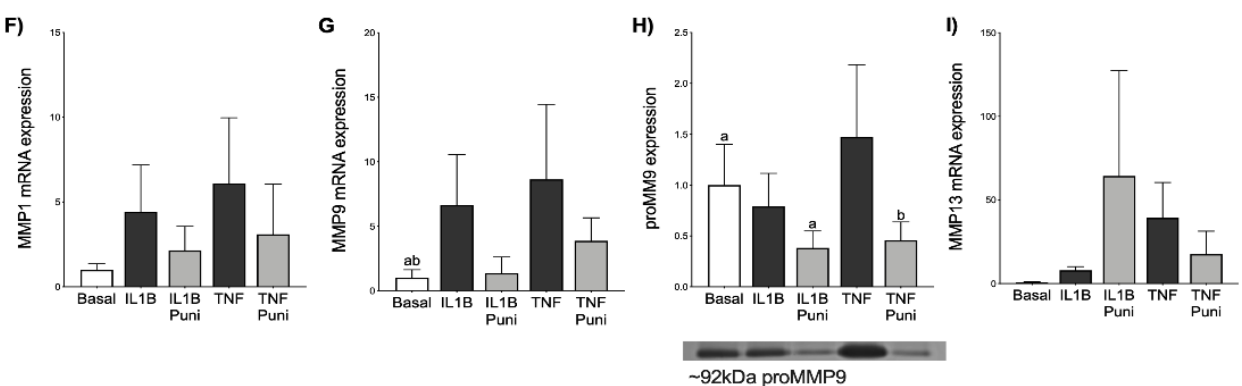

Fig. 7: Effect of punicalagin on MMP expression and activity in primary decidual and amnion cells. Human primary (A-E) decidual and (F-I) amnion cells were incubated in $1 \mathrm{ng} / \mathrm{mL}$ IL1B or $10 \mathrm{ng} / \mathrm{mL}$ TNF with or without $10 \mu \mathrm{M}$ punicalagin (Puni) for $20 \mathrm{~h}$ ( $\mathrm{n}=5$ patients). (A,F) MMP1, (B) MMP3, (C,G) MMP9 and (E,I) MMP13 mRNA expression was analysed by RT-qPCR. $(\mathrm{D}, \mathrm{H})$ ProMMP9 expression in the incubation media was assessed by gelatin zymography. Representative gel image from 1 patient/tissue is also shown. All data is displayed as mean \pm SEM. Statistical significance was determined using repeated measures one-way ANOVA; the symbol 'a' denotes statistical significance compared with IL1B $(P \leq 0.05)$, while the symbol 'b' denotes statistical significance compared with TNF $(P \leq 0.05)$ 
In primary decidual cells, IL1B significantly increased MMP1 mRNA expression compared with basal (Fig. 7A). TNF significantly also increased MMP1 and MMP9 mRNA expression and proMMP9 protein secretion compared with basal (Fig. 7A,C,D). There was no effect of IL1B on MMP3, MMP9, MMP13 mRNA expression and proMMP9 expression compared with basal (Fig. 7B-E). There was also no effect of TNF on MMP3 or MMP13 mRNA expression compared with basal (Fig. 7B,E). Punicalagin significantly decreased MMP3 mRNA expression in the presence of TNF (Fig. 7B) and IL1Band TNF-induced proMMP9 expression (Fig. 7D). There was, however, no effect of punicalagin on IL1B-induced MMP1, MMP3, MMP9 or MMP13 mRNA expression (Fig. 7A-C,E), or TNF-induced MMP1, MMP9 or MMP13 mRNA expression (Fig. 7A,C,E).

In primary amnion mesenchymal cells, IL1B significantly upregulated MMP9 mRNA expression and downregulated proMMP9 expression compared with basal (Fig. 7G,H), while TNF significantly increased MMP9 mRNA expression (Fig. 7G). There was no effect of IL1B or TNF on MMP1 or MMP13 mRNA expression (Fig. 7F,I). Punicalagin treatment significantly supressed proMMP9 protein secretion in the presence of IL1B or TNF (Fig. 7H). There was no effect of punicalagin on MMP1, MMP9 or MMP13 mRNA expression (Fig. 7F,G,I). MMP3 mRNA expression in amnion mesenchymal cells was non-detectable.

\section{Discussion}

To our knowledge, this is the first study to report that punicalagin suppresses expression of pro-inflammatory and pro-labor molecules in cells isolated from human myometrium and fetal membranes (refer Supplementary Table 1 for summary of results). In primary myometrial, decidual and amnion cells, punicalagin was able to block inflammation-induced increases in pro-inflammatory cytokines and chemokines. In primary myometrial and decidual cells, punicalagin suppressed the expression of $\mathrm{PGF}_{2 \alpha}$, which is involved in activating myometrial contractility. In support, functional studies demonstrated that punicalagin blocked inflammation-induced myometrial cell contractility. In cells isolated from the fetal membranes, punicalagin downregulated the expression of the ECMdegrading enzyme proMMP9. Collectively, these data suggest that punicalagin suppresses expression of proinflammatory and pro-labor mediators involved in labor onset and progression in human gestational tissues in vitro.

Inflammation plays a role in the pathophysiology of spontaneous preterm birth (Kim et al., 2013, Wenstrom et al., 1998). Pro-inflammatory cytokines such as IL1B and TNF induce production of pro-inflammatory mediators and propagate a pro-inflammatory cycle in these gestational tissues (Lappas, 2017, Lim et al., 2017,
Lappas et al., 2006). This inflammatory environment can then lead to downstream production of other pro-labor mediators to induce myometrial contractility (Rauk and Chiao, 2000) and fetal membrane rupture (Kumar et al., 2006). In this study, punicalagin significantly blocked inflammation-induced increases in pro-inflammatory cytokine mRNA expression and secretion, as well as chemokine protein secretion. Pro-inflammatory cytokines, such as IL1B, have previously been demonstrated to stimulate expression of contraction-associated proteins, uterotonics and ECM-degrading and -remodelling enzymes in human myometrial cells (Lappas, 2017). Similarly, IL1A, IL6 and GM-CSF are central to propagation of inflammation in preterm birth, as well as inducing uterine activation and fetal membrane weakening (Farina and Winkelman, 2005; Christiaens et al., 2008, Kumar et al., 2014). By downregulating mRNA expression and secretion of pro-inflammatory cytokines, punicalagin may then be able to prevent additional production of pro-inflammatory cytokines and chemokines, as well as downstream effects on myometrial contractility. Punicalagin was also noted to exert cell-specific effects on pro-inflammatory cytokine and chemokine expression and secretion; varying dosages and incubation times may elicit more comparable effects in each cell type. Interestingly, while punicalagin reduced protein secretion of most chemokines in myometrial, decidual and amnion cells, there was a weaker effect against their mRNA expression (for example, CCL2, CXCL1 and CXCL5). This may suggest that punicalagin regulates inflammatory secretion at a post-transcriptional level, rather than at the mRNA level. Regardless, by suppressing chemokine secretion into the incubation media, punicalagin may also limit leukocyte infiltration into intrauterine tissues, which is a known feature of laboring myometrium and fetal membranes (Hamilton et al., 2012, Thomson et al., 1999). Together, these findings suggest that punicalagin may be able to stem the propagation of pro-inflammatory mediators in myometrium and fetal membranes. The anti-inflammatory potential of punicalagin may then be able to block downstream effects on myometrial contractility and rupture of fetal membranes.

Myometrial contractility is mediated by way of contraction-associated proteins and the uterotonic $\mathrm{PGF}_{2 \alpha}$ (Roy et al., 2020). PTGS2 is the enzyme responsible for the production of $\mathrm{PGF}_{2 \alpha}$ in both myometrium (Olson, 2003) and decidua (Skinner and Challis, 1985). PGF $_{2 \alpha}$ can then induce myometrial contractility by binding with PTGFR (Olson, 2003 ) to induce cytoskeletal changes for contractility (Roy et al., 2020), as well as contribute to the production of pro-inflammatory mediators (Leimert et al., 2019). Previous studies found that $\mathrm{PGF}_{2 \alpha}$ treatment of pregnant mice induced early labor and abortion (Sugimoto et al., 1997, Shaw, 1983), while a PTGFR knockout model delayed parturition (Harper and Skarnes, 1972). 
Table 1: Summary of effects of punicalagin on IL1B- and TNF-treated primary human myometrial, decidual and amnion mesenchymal cells in vitro

\begin{tabular}{|c|c|c|c|c|c|c|}
\hline & \multicolumn{2}{|c|}{ Primary myometrial cells } & \multicolumn{2}{|c|}{ Primary decidual cells } & \multicolumn{2}{|c|}{$\begin{array}{l}\text { Primary amnion } \\
\text { mesenchymal cells }\end{array}$} \\
\hline & $\begin{array}{l}\text { Response to } \\
\text { IL1B }\end{array}$ & $\begin{array}{l}\text { Response } \\
\text { to TNF }\end{array}$ & $\begin{array}{l}\text { Response } \\
\text { to IL1B }\end{array}$ & $\begin{array}{l}\text { Response } \\
\text { to TNF }\end{array}$ & $\begin{array}{l}\text { Response } \\
\text { to IL1B }\end{array}$ & $\begin{array}{l}\text { Response } \\
\text { to TNF }\end{array}$ \\
\hline \multicolumn{7}{|c|}{ Pro-inflammatory cytokines } \\
\hline IL1A mRNA & $\downarrow$ & $\downarrow$ & - & $\downarrow$ & - & $\downarrow$ \\
\hline IL1B mRNA & NA & - & NA & $\downarrow$ & NA & $\downarrow$ \\
\hline IL6 mRNA & $\downarrow$ & - & - & - & - & - \\
\hline IL6 concentration & $\downarrow$ & $\downarrow$ & $\downarrow$ & $\downarrow$ & - & - \\
\hline GM-CSF mRNA & $\downarrow$ & - & - & - & - & - \\
\hline \multicolumn{7}{|c|}{ Pro-inflammatory chemokines } \\
\hline CCL2 mRNA & - & - & - & - & - & - \\
\hline CCL2 concentration & $\downarrow$ & $\downarrow$ & $\downarrow$ & $\downarrow$ & - & $\downarrow$ \\
\hline CCL8 mRNA & - & - & - & - & $\downarrow$ & - \\
\hline CXCL1 concentration & $\downarrow$ & $\downarrow$ & $\downarrow$ & $\downarrow$ & $\downarrow$ & - \\
\hline CXCL5 mRNA & - & - & - & - & - & $\downarrow$ \\
\hline CXCL5 concentration & $\downarrow$ & $\downarrow$ & $\downarrow$ & $\downarrow$ & $\downarrow$ & - \\
\hline CXCL8 mRNA & $\downarrow$ & $\downarrow$ & $\downarrow$ & $\downarrow$ & $\downarrow$ & $\downarrow$ \\
\hline CXCL8 concentration & $\downarrow$ & $\downarrow$ & $\downarrow$ & $\downarrow$ & $\downarrow$ & $\downarrow$ \\
\hline \multicolumn{7}{|c|}{ Prostaglandin pathway proteins } \\
\hline PTGS2 mRNA & $\downarrow$ & - & - & - & NA & NA \\
\hline PGF2 concentration & $\downarrow$ & $\downarrow$ & $\downarrow$ & $\downarrow$ & NA & NA \\
\hline \multicolumn{7}{|c|}{ Matrix metalloproteinases } \\
\hline MMP1 mRNA & NA & NA & - & - & - & - \\
\hline MMP3 mRNA & NA & NA & - & $\downarrow$ & NA & NA \\
\hline MMP9 mRNA & NA & NA & - & - & - & - \\
\hline proMMP9 expression & NA & NA & $\downarrow$ & $\downarrow$ & $\downarrow$ & $\downarrow$ \\
\hline MMP13 mRNA & NA & NA & - & - & NA & NA \\
\hline
\end{tabular}

\footnotetext{
Legend

$\downarrow$ significantly decreased compared to IL1B- or TNF-treated cells

$\uparrow$ significantly increased compared to IL1B- or TNF-treated cells

- no significant difference compared to IL1B- or TNF-treated cells

NA Not assessed
}

In this study, punicalagin suppressed inflammationinduced PTGS2 mRNA expression and $\mathrm{PGF}_{2 \alpha}$ secretion in myometrial cells. Punicalagin also reduced inflammation-induced $\mathrm{PGF}_{2 \alpha}$ secretion, but not PTGS2 mRNA expression, from decidual cells. This may suggest that punicalagin acts in a tissue-dependent manner to inhibit PGF2 $\alpha$ secretion - while punicalagin may target PTGS2 expression in myometrial cells, punicalagin may act on downstream enzymes, such as PGF synthases, in decidua cells. Importantly, punicalagin significantly prevented shrinkage of myometrial cell-embedded collagen gels in the presence of inflammation, indicating that punicalagin can suppress myometrial cell contractility. These data suggest that punicalagin targets the prostaglandin pathway to suppress prostaglandin secretion and inhibit myometrial contractility. This indicates that punicalagin may possess tocolytic properties and may be able to inhibit myometrial contractility associated with preterm birth.

Preterm premature rupture of membranes occurs through the weakening and rupture of the fetal membranes (Lannon et al., 2014). Matrix metalloproteinases are enzymes involved in ECM-remodelling and degradation that lead to weakening of the fetal membranes (Weiss et al., 2007). In amniotic fluid and maternal plasma, elevated levels of MMP1, MMP3 and MMP13 are associated with preterm birth (Park et al., 2003; Maymon et al., 2000; Soydinç et al., 2012; Fortunato et al., 1999). In fetal membranes, MMP9 protein expression is increased during and after labor (Tsatas et al., 1999), particularly localised to the site of rupture (Chai et al., 2013). Further, there is an inverse relationship between MMP9 and fetal membrane strength (El Khwad et al., 2005). These studies suggest a major contributing role for MMP9 in fetal membrane degradation. In this study, punicalagin downregulated MMP3 mRNA expression in decidual cells and proMMP9 expression in decidual and amnion mesenchymal cells. By targeting proMMP9 expression, punicalagin may be able to limit MMP9-associated fetal membrane weakening. Further, punicalagin inhibited proMMP9 expression, but not MMP1, MMP9 or MMP13 mRNA expression, suggesting that punicalagin may preferentially target protein expression or enzyme activity 
of MMPs. Additional studies exploring the effect of punicalagin on MMP protein expression and enzyme activity in the fetal membranes would provide further insight to the effect of punicalagin on fetal membrane weakening associated with preterm birth.

Collectively, these data show that punicalagin prevents expression of pro-inflammatory and pro-labor mediators in primary human gestational tissues. These findings suggest punicalagin may play a role in preventing intrauterine inflammation associated with human preterm birth. In a supplementary pilot study, pregnant mice were pre-treated with punicalagin for three days, prior to LPS administration to induce a pro-inflammatory intrauterine environment (Supplementary Fig. 1). These preliminary experiments show punicalagin can suppress expression of pro-inflammatory cytokines and chemokines in myometrium and decidua of an LPS mouse model of intrauterine inflammation (Supplementary Fig. 1). However, further research is required to effectively assess the impact of punicalagin on circulating levels of proinflammatory mediators, on prostaglandin-pathway proteins and MMP expression in an in vivo mouse model of intrauterine inflammation. Furthermore, the effect of punicalagin on delaying LPS-induced labor in pregnant mice remains unknown and warrants future research.

Intrauterine inflammation not only contributes to the pathophysiology of preterm birth, but has also been evidenced to alter fetal neuronal morphology in a mouse model of inflammation-induced preterm birth (Burd et al., 2010). It is of note, that previous studies have demonstrated a role for punicalagin and pomegranate juice in improved fetal neurodevelopmental outcomes. For example, a rat model of inflammation-induced fetal brain injury showed that pomegranate juice supplementation reduced fetal brain inflammation (Ginsberg et al., 2018). A recent human clinical trial in pregnant women with intrauterine growth restriction also found that, compared with a polyphenol-free placebo, pomegranate juice supplementation altered infant neural structure, in a manner that was indicative of improved maturation and neuroprotection (Matthews et al., 2019). These findings, together with the data presented in this study, may suggest that punicalagin may not only inhibit intrauterine inflammation, but may also contribute to fetal neuroprotection. Collectively, these studies suggest polyphenols may represent a novel strategy for targeted suppression of inflammation underlying preterm birth.

A number of strengths and limitations exist in this investigation. Firstly, the findings of the study are strengthened by using three distinct primary human cell lines derived from the critical tissues involved in preterm birth, including the myometrium and the fetal membranes (decidua and amnion mesenchyme). Secondly, the effect of punicalagin in vitro was measured in response to two different pro-inflammatory stimuli (IL1B and TNF), which each induce inflammation through distinct mechanisms (Lappas, 2017, Lim et al., 2017). While punicalagin suppressed intrauterine inflammation in pregnant mice, further studies are needed to determine if punicalagin can delay LPS-induced preterm labor in pregnant mice, as well as to identify the specific effects of punicalagin on fetal neurodevelopmental outcomes. Additional data on the effect of punicalagin on MMP protein secretion and activity would further complement the mRNA expression findings in this study. Finally, further investigation of the effect of punicalagin on mechanistic pathways, such as Akt/MAPK/NF- $\mathrm{BB}$ pathways may further strengthen the anti-inflammatory findings presented in this study.

Spontaneous preterm birth is the leading cause of neonatal morbidity and mortality; despite this, current intervention therapeutics benefit some, but not all, subsets of high-risk pregnancies (Beck et al., 2010, Haas et al., 2012). Here, we investigated the anti-inflammatory and anti-labor potential of punicalagin in an in vitro model of intrauterine inflammation associated with spontaneous preterm birth. In vitro, punicalagin suppressed inflammationinduced expression of pro-inflammatory cytokines, chemokines, prostaglandin pathway-associated proteins, uterotonics and MMPs involved in myometrial activation and fetal membrane rupture. Overall, this study found that punicalagin can suppress expression of pro-inflammatory and pro-labor molecules in vitro. Further study using an in vivo animal model is warranted to determine the efficacy of punicalagin in delaying preterm labor.

\section{Acknowledgements}

The following are gratefully acknowledged: Dr. Ratana Lim for her assistance with the in vivo mouse study, the clinical Research Midwives Gabrielle Pell, Genevieve Christophers and Rachel Murdoch for sample collection; the Obstetrics and Midwifery staff of the Mercy Hospital for Women for their co-operation; the women who generously donated their tissue samples to the study and the Austin BioResource Facility staff for the breeding, housing and maintenance of the mice.

\section{Funding}

This study was supported by project grants from the Norman Beischer Medical Research Foundation and the Austin Medical Research Foundation.

\section{Author Contributions}

Martha Lappas: Designed the study and critically reviewed the manuscript.

Caitlyn Nguyen-Ngo: Conducted the experiments, performed data analysis and wrote the initial draft of the manuscript. 
Jane C Willcox: Critically reviewed the study and the manuscript.

\section{Ethics}

This article is original and contains unpublished material. The corresponding author confirms that all of the other authors have read and approved the manuscript and no ethical issues involved.

\section{References}

Araujo, A. B., Furlan, J. M., Salton, G. D., Schmalfuss, T., Röhsig, L. M., Silla, L. M. R., ... \& Paz, A. H. (2018). Isolation of human mesenchymal stem cells from amnion, chorion, placental decidua and umbilical cord: Comparison of four enzymatic protocols. Biotechnology letters, 40(6), 989-998. doi.org/10.1007/s10529-018-2546-Z

Asres, K., Bucar, F., Knauder, E., Yardley, V., Kendrick, H., \& Croft, S. L. (2001). In vitro antiprotozoal activity of extract and compounds from the stem bark of Combretum molle. Phytotherapy Research, 15(7), 613-617. doi.org/10.1002/ptr.897

Beck, S., Wojdyla, D., Say, L., Betran, A. P., Merialdi, M., Requejo, J. H., ... \& Van Look, P. F. (2010). The worldwide incidence of preterm birth: A systematic review of maternal mortality and morbidity. Bulletin of the World Health Organization, 88, 31-38. doi.org/10.2471/BLT.08.062554

Bensaad, L. A., Kim, K. H., Quah, C. C., Kim, W. R., \& Shahimi, M. (2017). Anti-inflammatory potential of ellagic acid, gallic acid and punicalagin A\&B isolated from Punica granatum. BMC complementary and alternative medicine, 17(1), 1-10. doi.org/10.1186/s12906-017-1555-0

Burd, I., Bentz, A. I., Chai, J., Gonzalez, J., Monnerie, H., Le Roux, P. D., ... \& Elovitz, M. A. (2010). Inflammation-induced preterm birth alters neuronal morphology in the mouse fetal brain. Journal of neuroscience research, 88(9), 1872-1881. doi.org/10.1002/jnr.22368

Chai, M., Walker, S. P., Riley, C., Rice, G. E., Permezel, M., \& Lappas, M. (2013). Effect of supracervical apposition and spontaneous labour on apoptosis and matrix metalloproteinases in human fetal membranes. BioMed research international, 2013. doi.org/10.1155/2013/316146

Chen, B., Tuuli, M. G., Longtine, M. S., Shin, J. S., Lawrence, R., Inder, T., \& Michael Nelson, D. (2012). Pomegranate juice and punicalagin attenuate oxidative stress and apoptosis in human placenta and in human placental trophoblasts. American Journal of Physiology-Endocrinology and Metabolism, 302(9), E1142-E1152. doi.org/10.1152/ajpendo.00003.2012
Chen, Z., Liu, Q., Zhu, Z., Xiang, F., Wu, R., \& Kang, X. (2020). Toll-like receptor 4 contributes to uterine activation by upregulating pro-inflammatory cytokine and CAP expression via the NF$\kappa \mathrm{B} / \mathrm{P} 38 \mathrm{MAPK}$ signaling pathway during pregnancy. Journal of cellular physiology, 235(1), 513-525. doi.org/10.1002/jcp.28991

Christiaens, I., Zaragoza, D. B., Guilbert, L., Robertson, S. A., Mitchell, B. F., \& Olson, D. M. (2008). Inflammatory processes in preterm and term parturition. Journal of reproductive immunology, 79(1), 50-57. doi.org/10.1016/j.jri.2008.04.002

El Khwad, M., Stetzer, B., Moore, R. M., Kumar, D., Mercer, B., Arikat, S., ... \& Moore, J. J. (2005). Term human fetal membranes have a weak zone overlying the lower uterine pole and cervix before onset of labor. Biology of reproduction, 72(3), 720-726. doi.org/10.1095/biolreprod.104.033647

Englund-Ögge, L., Brantsæter, A. L., Sengpiel, V., Haugen, M., Birgisdottir, B. E., Myhre, R., ... \& Jacobsson, B. (2014). Maternal dietary patterns and preterm delivery: Results from large prospective cohort study. Bmj, 348. doi.org/10.1136/bmj.g1446

Fortunato, S. J., Menon, R., \& Lombardi, S. J. (1999). MMP/TIMP imbalance in amniotic fluid during PROM: An indirect support for endogenous pathway to membrane rupture. doi.org/10.1515/JPM.1999.049

Farina, L., \& Winkelman, C. (2005). A review of the role of proinflammatory cytokines in labor and noninfectious preterm labor. Biological research for nursing, 6(3), 230-238.

Gilman-Sachs, A., Dambaeva, S., Garcia, M. D. S., Hussein, Y., Kwak-Kim, J., \& Beaman, K. (2018). Inflammation induced preterm labor and birth. Journal of reproductive immunology, 129, 53-58. doi.org/10.1016/j.jri.2018.06.029

Ginsberg, Y., Khatib, N., Saadi, N., Ross, M. G., Weiner, Z., \& Beloosesky, R. (2018). Maternal pomegranate juice attenuates maternal inflammation-induced fetal brain injury by inhibition of apoptosis, neuronal nitric oxide synthase and NF- $\mathrm{KB}$ in a rat model. American journal of obstetrics and gynecology, 219(1), 113-e1. doi.org/10.1016/j.ajog.2018.04.040

Goldenberg, R. L., Hauth, J. C., \& Andrews, W. W. (2000). Intrauterine infection and preterm delivery. New England Journal of Medicine, 342, 1500-7. doi.org/10.1056/NEJM200005183422007

Haas, D. M., Caldwell, D. M., Kirkpatrick, P., McIntosh, J. J., \& Welton, N. J. (2012). Tocolytic therapy for preterm delivery: Systematic review and network meta-analysis. Bmj, 345. doi.org/10.1136/bmj.e6226

Hamilton, S., Oomomian, Y., Stephen, G., Shynlova, O., Tower, C. L., Garrod, A., ... \& Jones, R. L. (2012). Macrophages infiltrate the human and rat decidua during term and preterm labor: Evidence that decidual inflammation precedes labor. Biology of reproduction, 86(2), 39-1. doi.org/10.1095/biolreprod.111.095505 
Harper, M. J. K., \& Skarnes, R. C. (1972). Inhibition of abortion and fetal death produced by endotoxin or prostaglandin F2 $\alpha$. Prostaglandins, 2(4), 295-309. doi.org/10.1016/S0090-6980(72)80017-0

Kang, B., Kim, C. Y., Hwang, J., Jo, K., Kim, S., Suh, H. J., \& Choi, H. S. (2019). Punicalagin, a PomegranateDerived Ellagitannin, Suppresses Obesity and Obesity-Induced Inflammatory Responses Via the Nrf2/Keap1 Signaling Pathway. Molecular nutrition \& food research, 63(22), 1900574 doi.org/10.1002/mnfr.201900574

Kim, A., Lee, E. S., Shin, J. C., \& Kim, H. Y. (2013). Identification of biomarkers for preterm delivery in mid-trimester amniotic fluid. Placenta, 34(10), 873-878. doi.org/10.1016/j.placenta.2013.06.306

Kumar, D., Fung, W., Moore, R. M., Pandey, V., Fox, J., Stetzer, B., ... \& Moore, J. J. (2006). Proinflammatory cytokines found in amniotic fluid induce collagen remodeling, apoptosis and biophysical weakening of cultured human fetal membranes. Biology of reproduction, 74(1), 29-34. doi.org/10.1095/biolreprod.105.045328

Kumar, D., Moore, R. M., Nash, A., Springel, E., Mercer, B. M., Philipson, E., ... \& Moore, J. J. (2014). Decidual GM-CSF is a critical common intermediate necessary for thrombin and TNF induced in-vitro fetal membrane weakening. Placenta, 35(12), 1049. 1056. doi.org/10.1016/j.placenta.2014.10.001

Lannon, S. M., Vanderhoeven, J. P., Eschenbach, D. A., Gravett, M. G., \& Waldorf, K. M. A. (2014). Synergy and interactions among biological pathways leading to preterm premature rupture of membranes. Reproductive sciences, 21(10), 1215-1227. doi.org/10.1177/1933719114534535

Lappas, M. (2017). The IL-1 $\beta$ signalling pathway and its role in regulating pro-inflammatory and pro-labour mediators in human primary myometrial cells. Reproductive Biology, 17(4), 333-340. doi.org/10.1016/j.repbio.2017.09.006

Lappas, M., Yee, K., Permezel, M., \& Rice, G. E. (2006). Lipopolysaccharide and TNF- $\alpha$ activate the nuclear factor kappa B pathway in the human placental JEG-3 cells. Placenta, 27(6-7), 568-575. doi.org/10.1016/j.placenta.2005.06.003

Leimert, K. B., Verstraeten, B. S., Messer, A., Nemati, R., Blackadar, K., Fang, X., ... \& Olson, D. M. (2019). Cooperative effects of sequential PGF $2 \alpha$ and IL- $1 \beta$ on IL-6 and COX-2 expression in human myometrial cells. Biology of reproduction, 100(5), 1370-1385. doi.org/10.1093/biolre/ioz029

Lim, R., \& Lappas, M. (2019). Expression and function of macrophage-inducible C-type lectin (Mincle) in inflammation driven parturition in fetal membranes and myometrium. Clinical \& Experimental Immunology, 197(1), 95-110. doi.org/10.1111/cei.13281
Lim, R., Barker, G., \& Lappas, M. (2013a). A novel role for FOXO3 in human labor: Increased expression in laboring myometrium and regulation of proinflammatory and prolabor mediators in pregnant human myometrial cells. Biology of reproduction, 88(6), 156-1. doi.org/10.1095/biolreprod.113.108126

Lim, R., Barker, G., \& Lappas, M. (2013b). SIRT6 is decreased with preterm labor and regulates key terminal effector pathways of human labor in fetal membranes. Biology of reproduction, 88(1), 17-1. doi.org/10.1095/biolreprod.112.105163

Lim, R., Barker, G., \& Lappas, M. (2017). TRADD, TRAF 2 , RIP 1 and TAK 1 are required for TNF- $\alpha$-induced pro-labour mediators in human primary myometrial cells. American Journal of Reproductive Immunology, 78(1), e12664. doi.org/10.1111/aji.12664

Lim, R., Barker, G., Wall, C. A., \& Lappas, M. (2013c). Dietary phytophenols curcumin, naringenin and apigenin reduce infection-induced inflammatory and contractile pathways in human placenta, foetal membranes and myometrium. Molecular human reproduction, 19(7), 451-462. doi.org/10.1093/molehr/gat015

Lim, R., Morwood, C. J., Barker, G., \& Lappas, M. (2014). Effect of silibinin in reducing inflammatory pathways in in vitro and in vivo models of infectioninduced preterm birth. PLoS One, 9(3), e92505. doi.org/10.1371/journal.pone.0092505

Manach, C., Scalbert, A., Morand, C., Rémésy, C., \& Jiménez, L. (2004). Polyphenols: Food sources and bioavailability. The American journal of clinical nutrition, 79(5), 727-747. doi.org/10.1093/ajcn/79.5.727

Marzouk, M. S., El-Toumy, S. A., \& Moharram, F. A. (2002). Pharmacologically active ellagitannins from Terminalia myriocarpa. Planta medica, 68(06), 523-527. doi.org/10.1055/s-2002-32549

Matthews, L. G., Smyser, C. D., Cherkerzian, S., Alexopoulos, D., Kenley, J., Tuuli, M. G., ... \& Inder, T. E. (2019). Maternal pomegranate juice intake and brain structure and function in infants with intrauterine growth restriction: A randomized controlled pilot study. PloS one, 14(8), e0219596. doi.org/10.1371/journal.pone.0219596

Maymon, E., Romero, R., Pacora, P., Gervasi, M. T., Bianco, K., Ghezzi, F., \& Yoon, B. H. (2000). Evidence for the participation of interstitial collagenase (matrix metalloproteinase 1) in preterm premature rupture of membranes. American journal of obstetrics and gynecology, 183(4), 914-920. doi.org/10.1067/mob.2000.108879

Morwood, C. J., \& Lappas, M. (2014). The citrus flavone nobiletin reduces pro-inflammatory and pro-labour mediators in fetal membranes and myometrium: Implications for preterm birth. PloS one, 9(9), e108390. doi.org/10.1371/journal.pone.0108390 
Mwaniki, M. K., Atieno, M., Lawn, J. E., \& Newton, C. R. (2012). Long-term neurodevelopmental outcomes after intrauterine and neonatal insults: A systematic review. The Lancet, 379(9814), 445-452. doi.org/10.1097/OGX.0b013e31825bbd63

Myhre, R., Brantsæter, A. L., Myking, S., Eggesbø, M., Meltzer, H. M., Haugen, M., \& Jacobsson, B. (2013). Intakes of garlic and dried fruits are associated with lower risk of spontaneous preterm delivery. The Journal of nutrition, 143(7), 1100-1108. doi.org/10.3945/jn.112.173229

Nguyen-Ngo, C., Salomon, C., Lai, A., Willcox, J. C., \& Lappas, M. (2020). Anti-inflammatory effects of gallic acid in human gestational tissues in vitro. Reproduction, 160(4), 561-578. doi.org/10.1530/REP-20-0249

Olson, D. M. (2003). The role of prostaglandins in the initiation of parturition. Best practice \& research Clinical obstetrics \& gynaecology, 17(5), 717-730. doi.org/10.1016/S1521-6934(03)00069-5

Olson, D. M., \& Ammann, C. (2007). Role of the prostaglandins in labour and prostaglandin receptor inhibitors in the prevention of preterm labour. Front Biosci, 12(1), 1329-1343. doi.org/10.2741/2151

Park, K. H., Chaiworapongsa, T., Kim, Y. M., Espinoza, J., Yoshimatsu, J., Edwin, S., ... \& Romero, R. (2003). Matrix metalloproteinase 3 in parturition, premature rupture of the membranes and microbial invasion of the amniotic cavity. doi.org/10.1515/JPM.2003.002

Peng, J., Wei, D., Fu, Z., Li, D., Tan, Y., Xu, T., ... \& Zhang, T. (2015). Punicalagin ameliorates lipopolysaccharide-induced acute respiratory distress syndrome in mice. Inflammation, 38(2), 493-499. doi.org/10.1007/s10753-014-9955-5

Petrou, S., Yiu, H. H., \& Kwon, J. (2019). Economic consequences of preterm birth: A systematic review of the recent literature (2009-2017). Archives of disease in childhood, 104(5), 456-465. doi.org/10.1136/archdischild-2018-315778

Rauk, P. N., \& CHIAO, J. P. (2000). Interleukin-1 stimulates human uterine prostaglandin production through induction of cyclooxygenase- 2 expression. American Journal of Reproductive Immunology, 43(3), 152-159. doi.org/10.1111/j.8755-8920.2000.430304.X

Romero, R., Quintero, R., Oyarzun, E., Wu, Y. K., Sabo, V., Mazor, M., \& Hobbins, J. C. (1988). Intraamniotic infection and the onset of labor in preterm premature rupture of the membranes. American journal of obstetrics and gynecology, 159(3), 661-666. doi.org/10.1016/S0002-9378(88)80030-9

Rothwell, J. A., Perez-Jimenez, J., Neveu, V., MedinaRemon, A., M'hiri, N., García-Lobato, P., ... \& Scalbert, A. (2013). Phenol-Explorer 3.0: A major update of the Phenol-Explorer database to incorporate data on the effects of food processing on polyphenol content. Database, 2013. doi.org/10.1093/database/bat070
Roy, R., Nguyen-Ngo, C., \& Lappas, M. (2020). Shortchain fatty acids as novel therapeutics for gestational diabetes. Journal of Molecular Endocrinology, 65(2), 21-34. doi.org/10.1530/JME-20-0094

Shaw, G. (1983). Effect of PGF-2 $\alpha$ on uterine activity and concentrations of 13,14 -dihydro-15-keto-PGF-2 $\alpha$ in peripheral plasma during parturition in the tammar wallaby (Macropus eugenii). Reproduction, 69(2), 429-436. doi.org/10.1530/jrf.0.0690429

Skinner, K. A., \& Challis, J. R. (1985). Changes in the synthesis and metabolism of prostaglandins by human fetal membranes and decidua at labor. American journal of obstetrics and gynecology, 151(4), 519-523. doi.org/10.1016/0002-9378(85)90281-9

Soydinç, H. E., Sak, M. E., Evliyaoğlu, O., Evsen, M. S., Turgut, A., Özler, A., ... \& Gül, T. (2012). Maternal plasma prolidase, matrix metalloproteinases 1 and 13 and oxidative stress levels in pregnancies complicated by preterm premature rupture of the membranes and chorioamnionitis. Journal of the Turkish German Gynecological Association, 13(3), 172. doi.org/10.5152/jtgga.2012.23

Sugimoto, Y., Yamasaki, A., Segi, E., Tsuboi, K., Aze, Y., Nishimura, T., ... \& Narumiya, S. (1997). Failure of parturition in mice lacking the prostaglandin $\mathrm{F}$ receptor. Science, 277(5326), 681-683.

https://www.science.org/doi/abs/10.1126/science.27 7.5326.681

Thomson, A. J., Telfer, J. F., Young, A., Campbell, S., Stewart, C. J., Cameron, I. T., ... \& Norman, J. E. (1999). Leukocytes infiltrate the myometrium during human parturition: Further evidence that labour is an inflammatory process. Human reproduction, 14(1), 229-236. doi.org/10.1093/humrep/15.1.229

Tsatas, D., Baker, M. S., \& Rice, G. E. (1999). Differential expression of proteases in human gestational tissues before, during and after spontaneous-onset labour at term. Reproduction, 116(1), 43-49. doi.org/10.1530/jrf.0.1160043

Vadillo-Ortega, F., \& Estrada-Gutiérrez, G. (2005). Role of matrix metalloproteinases in preterm labour. BJOG: An International Journal of Obstetrics \& Gynaecology, 112, 19-22. doi.org/10.1111/j.1471-0528.2005.00579.x

Wall, C., Lim, R., Poljak, M., \& Lappas, M. (2013). Dietary flavonoids as therapeutics for preterm birth: Luteolin and kaempferol suppress inflammation in human gestational tissues in vitro. Oxidative medicine and cellular longevity, 2013. doi.org/10.1155/2013/485201

Weiss, A., Goldman, S., \& Shalev, E. (2007). The matrix metalloproteinases (MMPS) in the decidua and fetal membranes. Front Biosci, 12(1), 649-659. doi.org/10.2741/2089 
Wenstrom, K. D. andrews, W. W., Hauth, J. C., Goldenberg, R. L., DuBard, M. B., \& Cliver, S. P. (1998). Elevated second-trimester amniotic fluid interleukin-6 levels predict preterm delivery. American journal of obstetrics and gynecology, 178(3), 546-550. doi.org/10.1016/S0002-9378(98)70436-3

Wijesuriya, Y. K., \& Lappas, M. (2018). Potent antiinflammatory effects of honokiol in human fetal membranes and myometrium. Phytomedicine, 49, 11-22. doi.org/10.1016/j.phymed.2018.06.004
Xu, X., Yin, P., Wan, C., Chong, X., Liu, M., Cheng, P., ... \& Xu, J. (2014). Punicalagin inhibits inflammation in LPS-induced RAW264. 7 macrophages via the suppression of TLR4-mediated MAPKs and NF- $\mathrm{BB}$ activation. Inflammation, 37(3), 956-965. doi.org/10.1007/s10753-014-9816-2

Zhong, J., Reece, E. A., \& Yang, P. (2015). Punicalagin exerts protective effect against high glucose-induced cellular stress and neural tube defects. Biochemical and biophysical research communications, 467(2), 179-184. doi.org/10.1016/j.bbrc.2015.10.024 